\title{
Kierkegaard y Woody Allen: El humor como condición ética del devenir existencial del individuo
}

\author{
Melinda and Melinda | Woody Allen | 2004 \\ Rafael García Pavón* \\ Universidad Anáhuac México
}

Recibido 26 de agosto de 2020; 10 de noviembre de 2020

\begin{abstract}
Resumen
En el presente trabajo se analiza el humor como condición ética para la forma de ser y de pensar del devenir existencial del individuo, desde la concepción de Kierkegaard a la forma de la filosofía cinemática de los films de Woody Allen. El devenir existencial en Kierkegaard no se deriva o reduce a la lógica de una dialéctica o de las condiciones naturales, sino que depende esencialmente de la elección de sí mismo, como vínculo entre lo que se ha sido y lo que está por venir, lo cual constituye lo ético. Esta contradicción específica es el humor, como la tensión de lo trágico y lo cómico en la existencia, y en el pensador subjetivo de Kierkegaard, para el cual lo trágico se da cuando las pretensiones infinitas no se delimitan en la contradicción específica de la existencia individual y lo cómico se da como una relativización de las mismas, de este modo el devenir se realiza cuando en lo trágico hay un equilibrio cómico, y en lo cómico se denota el patetismo de lo trágico, dando lugar a esa condición de apertura constante de posibilidades nuevas, que permite plantearse la elección de sí mismo, como querer creer que es posible de nuevo un lazo de sentido a pesar del sinsentido de los hechos. Precisamente, la motivación de los films de Woody Allen filosóficamente, tienen que ver con esta cuestión en forma de pregunta, que se desarrolla, en general, en su obra fílmica, como la maduración de un humor, donde tragedia y comedia se relacionan recíprocamente, lo cual permite pensar subjetivamente-existencialmente como lo ha planteado Kierkegaard. En particular se analiza el planteamiento en el film de Woody Allen Melinda and Melinda del año 2004.
\end{abstract}

Palabras Clave: humor | cómico | trágico | Woody Allen | Kierkegaard | subjetividad

Kierkegaard and Woody Allen: Humor as the ethical condition of the existential becoming of the individual

\begin{abstract}
In this paper, humor is analyzed as an ethical condition for the way of being and thinking of the existential becoming of the individual from the conception of Kierkegaard as the form of the cinematic philosophy of Woody Allen's films. The existential becoming in Kierkegaard is not derived or reduced to the logic of a dialectic or of natural conditions, but depends essentially on the choice of oneself as the link between what has been and what is to come, which constitutes the ethical. This specific contradiction is humor, as the tension of the tragic and the comic in existence and in Kierkegaard's subjective thinker, for which the tragic occurs when the infinite claims are not delimited in the specific contradiction of individual existence and the comic is given as a relativization of the same, in this way the becoming takes place when in the tragic there is a comic balance and in the comic the pathos of the tragic is denoted, giving rise to that condition of constant opening of new possibilities, that allows considering the choice of oneself, like wanting to believe that a bond of meaning is possible again despite the nonsense of the facts. Precisely the motivation of Woody Allen's films philosophically has to do with this question in the form of a fundamental interrogation and it develops in general in his film work as the maturation of a humor where tragedy and comedy are reciprocally related, which allows to think subjectively-existentially as Kierkegaard has put it. In particular, the approach in Woody Allen's film Melinda and Melinda from 2004 is analyzed.
\end{abstract}

Keywords: humor | tragedy | comic | Woody Allen | Kierkegaard | subjectivity

Motto:

"Todo el mundo me exaspera. Pero me gusta reír.,
Y no puedo reir solo."
E. M. Cioran (2010, p. 134)

"Nuestros cuerpos, desnudos aún, estaban entrelazados. Yo fumaba y miraba el techo.

-Claire, ¿y si Kierkegaard twviera razón?
-¿Qué quieres decir?

-Si realmente jamás se pudiera saber. Sólo tener fe.

- Esto es absurdo.

- No seas tan racionalista.

-Nadie es racionalista Kaiser. -Encendió un cigarrillo- Lo unico que te pido es que no empieces con la ontología. No en este momento. No podría aguantar que fueras ontólogo conmigo, Kaiser."

Woody Allen (1997, p. 107)

*gclimacus71@gmail.com 


\section{Introducción}

Woody Allen es reconocido dentro de la historia de la cinematografía norteamericana ${ }^{1}$, no solo como uno de los cineastas más prolíficos ${ }^{2}$, sino como un autor ${ }^{3}$ en la medida que sus films presentan ideas constantes sobre temas psicológicos, románticos o existenciales (Lax, 2009). Dichos filmes expresan cierta consistencia formal y temática, en una tensión entre comedia y drama, que el mismo Allen ha aprendido a desarrollar como un modo de pensar humorístico sobre aquello que le preocupa en toda su obra, como le dice a Eric Lax (2009) en una de sus múltiples entrevistas:

Algo que siempre me ha fascinado y he tratado en otras de mis películas es esa crisis a la que llegó Tolstoi, cuando en un momento de su vida, vio que no entendía porque no debía suicidarse ¿Merece la pena vivir en un mundo sin Dios? La mente dice que no, pero el corazón tiene demasiado miedo para tomar una medida drástica que acabe con todo. (p. 123)

Lo cual denota una interrogante de carácter filosófico fundamental, como ya lo había planteado Albert Camus (2002) en el Mito de Sísifo, cuando expresaba que "la pregunta por el suicidio era lo único filosóficamente serio, porque las acciones a las que compromete hacen la diferencia entre la vida y la muerte" (p.13). Podríamos decir que un aspecto importante de Woody Allen como autor es ser un cineasta que expresa un modo de pensar filosófico en la forma particular del humor o, dicho de otra manera, que el humor de los films de Woody Allen es un modo de pensar filosófico centrado en este problema de carácter existencial y ético. El modo en que Woody Allen filma las decisiones de sus personajes lo confirma, porque lo importante no son los actos en sí, sino cómo a través de estos se hace posible la reflexión sobre las cuestiones éticas y metafísicas:

La única explicación que puedo dar es que, dada mi condición de escritor por encima de todo lo demás, para mí todo ese material se convierte en un pretexto en torno al cual exponer mis ideas y filosofar. No me interesa el acto del asesinato en sí mismo. El crimen se da para que los protagonistas puedan hablar de Dios y la culpa. (Lax, 2009, p. 174)

A pesar de que el mismo Allen, con honestidad, ha dicho que no es ninguna suerte de intelectual, e inclusive es famoso su gag donde compara a los filósofos con los gangsters -porque se matan entre ellos-, lo cierto es que en sus films abundan las referencias a íconos de la literatura como Dostoievsky ${ }^{4}$, del cine de autor espiritual, como su querido Ingmar Bergman 5 o Federico Fellini, siendo la filosofía por la que que ha expresado un especial interés, como le comentó a Eric Lax:
La filosofía era algo que me interesaba sin saberlo. Enseguida me aficioné a ella, y el hecho de que Harlene (...) estudiara filosofía era muy estimulante para mí. Si me hubiera replanteado mi educación, seguramente habría ido a la universidad para estudiar filosofía. (2009, p. 117)

En su reciente autobiografía, $A$ propósito de nada (Allen, 2020), ha vuelto a confirmar esto: "Gracias a ella (Harlene, su primera esposa) me he familiarizado un poco con Kant, Kierkegaard, Schopenhauer y Hegel” (p. 126).

Entre las menciones que hace de los filósofos podemos encontrar de forma intencionada, cómica y seria, referencias ímplictas y explícitas a Kierkegaard ${ }^{6}$, además de que hay estudios sobre el cineasta neoyorquino, específicamente desde el pensamiento de Kierkegaard ${ }^{7}$. De cierta manera hay una afinidad entre las preocupaciones de Allen y el pensamiento existencial del danés, en cuanto a la idea del humor como la forma propia del pensamiento, ante la pregunta ético-existencial sobre el sentido de la vida, cuando a los ojos de la conciencia no parece tener ninguno de antemano.

Tanto para Allen como para Kierkegard, el humor es un modo de pensar a través del cual se mira a lo realmente serio e importante de la vida. Esto es, la elección radical de ser sí mismo en la condición de que la existencia es incongruente, como lo ha dicho Stephen Evans (1987) en su artículo "Kierkegaard's View of Humor: Must Christians always be solemn?" ante la pregunta de si hay contemporáneos que puedan ser la descripción del humorista según Kierkegaard: "Creo que los hay. Woody Allen y Garrison Keillor (...) en sus films Allen ha ilustrado mejor que nadie que yo conozca la incongruencia básica de la vida humana" (pp. 184-185).

Algunos podrían objetar que esto no es exacto, porque la filosofía del humor de Kierkegaard tiene una tendencia claramente religiosa y cristiana, y en Allen termina siendo un modo de escepticismo o de franco nihilismo, en donde todo queda en una absoluta relatividad. Sin embargo, la convergencia del sentido del humor en Kierkegaard y Allen se parece al diálogo de los personajes del texto de Kierkegaard (2005) A la espera de la fe con ocasión del año nuevo en el cual tres amigos, un escéptico, un creyente y un nihilista discuten acerca de qué sería lo mejor que le pueden desear al otro en el año nuevo, concluyéndo que es la fe, pero que nadie se la puede dar al otro.

Si hacemos un silencio musical y una pausa en el ritmo fílmico, podríamos imaginarnos a todos brindando y riéndose de sí mismos, porque el humor relativiza la falsa seriedad de todos ellos y los deja en la situación de que la fe no se reduce a ninguno de sus argumentos o formas 
de vida, sino que es algo más a lo que la risa los abre, esto es, vivir a la espera de la fe. Es esta experiencia, vivencia o condición existencial de apertura, independiente de la fe revelada en particular, lo que Kierkegaard considera como el carácter específico del pensador subjetivo o existencial, a partir de la cual se plantea la libertad como salto cualitativo de forma radical ${ }^{8}$.

Por lo tanto, el objetivo de este trabajo es plantear que en los films de Woody Allen, en general, se muestra una forma del humor que se puede entender como la del pensador subjetivo-existencial de Kierkegaard o, dicho de otra forma, que la filosofía cinemática del humor de los films de Woody Allen es la del pensador subjetivo de Kierkegaard.

El humor integra lo cómico y lo trágico, como modos ser y de pensar el devenir del individuo singular en la existencia. Tanto lo cómico, como lo trágico, expresan lo que Kierkegaard llama el sentido negativo de la subjetividad; es decir, la desproporción entre las pretensiones del pensamiento y el acontecimiento de la realidad, en donde la síntesis no se da por la mediación de la lógica dialéctica, sino por el salto cualitativo de elegirse como un vínculo dinámico entre lo conocido y lo que está por venir. De otro modo, la sola tragedia lleva al individuo a la fatalidad y la sola comicidad lo pierde en la locura, pero el humor los mantiene en tensión. Lo cual equivale al flujo del devenir en la existencia, cuya característica fundamental es mantener siempre esa apertura del espíritu como la disposición y el acto de elegirse para recibirse a sí mismo (Kierkegaard, 2007).

Aunque Kierkegaard se declare un creyente en la fe cristiana y Woody Allen un ateo o un escéptico, en el humor se encuentran ante la misma situación que hace posible que la vida tenga sentido, a pesar del sinsentido objetivo de los hechos, esto es, la posibilidad de elegir el elegir mismo. Ni en Kierkegaard la elección de la fe está desprovista de tensión, ni la no-elección de la misma en Woody Allen está cerrada a otra posibilidad. Diríamos que el humor es una forma de vivir y, al mismo tiempo, es la forma de pensar la existencia cinemáticamente9.

Para ello, primero expondremos el sentido del humor como esa tensión dinámica entre lo cómico y lo trágico que constituyen la forma del pensador subjetivo en Kierkegaard; en segundo lugar, describiremos sus resonancias en los films de Woody Allen, para terminar con un análisis breve del film de 2004 Melinda and Melinda, porque en él la trama es una representación de esta tensión de lo cómico y lo trágico como formas de ser de las relaciones entre la existencia y el cine.

\section{El humor como forma de ser del pensador subjetivo: lo trágico y lo cómico}

Esta idea de que el encuentro entre el creyente y el ateo, al final del año nuevo, termina en un testimonio de una verdadera amistad -desearle dar la fe al otro, aunque sea imposible- es el acto de reírse de sí mismo, que se considera como lo esencial del pensador subjetivo, porque relativiza su falsa seriedad o su falsa positividad en el mundo y a su vez es el modo esencial del humor. Como nos dice Vittorio Hösle (2002) en su texto Filosofía del bumor en los films de Woody Allen:

La cualidad decisiva es en todo caso la capacidad de la persona cómica de reírse de sí misma: al hacerlo, se une a los espectadores o lectores, y éstos, al tener ese rasgo común, se inclinarán más bien a identificarse y se reirán con ella, no de ella. (p. 29)

En casi todos los films de Woody Allen, el personaje protagónico se ríe de sí mismo y sobre el sentido de ser protagónico, algo así como un "yo" -en el sentido del sujeto moderno ${ }^{10}$ - que se ríe de serlo, por lo cual se hace completamente cómico como prisma de lo serio.

De algún modo, el tema del humor como ese reírse de la propia pretensión o de la adjudicada por el mundo, es la forma en que el autor seudónimo de Kierkegaard de Migajas filosóficas y de El Postscriptum (2009) Johannes Climacus, se presenta a sí mismo y a sus escritos: “Todo esto me lleva a la perplejidad trágico-cómico de tener que reírme de mi propia desgracia” (Kierkegaard, 2016, p. 28). Porque estos escritos son el resultado del fracaso de la falsa pretensión de la duda cartesiana, y de la dialéctica hegeliana de generar la existencia, o de ser una forma de vida, como Johannes Climacus ha escrito en $\mathrm{El} d u d a r$ de todas las cosas (Kierkegaard, 2007b). Podría decirse entonces, que las ideas del pensador subjetivo son producto del humor de reírse de sí mismo, pero por donde asoma lo realmente serio. Esto significa la apertura a la elección de sí mismo como porvenir, y no como proceso dialéctico.

Los personajes de Woody Allen y sus films son, en general, un reírse de los atributos del mundo moderno como modos de ser de la persona -por los cuales la persona se pierde, por ello hay que reírse de ellos- presentando de este modo la condición humana en la existencia:

su valentía es ser un cobarde militante, su belleza es ser lo suficientemente feo para amar, su armonía es su constante fragmentación reflexiva, su efectividad en el mundo es su absoluta incomprensión del mundo tecnológico, su fundamentalismo es ser siempre un escéptico lleno de dudas $y$, finalmente, su fama es ser absolutamente individual y singular. (Lax, 2009, p.92) 
Lo serio detrás de lo cómico implica que solo hay una forma de vivir la existencia, esto es, personalmente, individualmente; descubriendo nuestra singularidad, más allá de lo que la reflexividad nos define, en la relación de amor que lleva a la persona fuera de sí. Así lo expresa el personaje de Mickey (Woody Allen) en Hannab and Her Sisters (Allen, 1986) después de haber consultado a la filosofía, a las religiones e inclusive a su piscoanalista: "probablemente tengan razón los poetas y la respuesta está en el amor" o como el profesor Louis Levy (Martin Bergmann) dice al final de la película Crimes and Misdemeanors (Allen, 1989b):

"Somos solo nosotros, con nuestra capacidad de amar, que le damos significado al universo indiferente. $Y$ aún así, la mayoría de los seres humanos parecen tener la babilidad de seguir intentando, y aún abi encontrar gozo, de cosas simples como la familia, su trabajo, y de la esperanza de que futuras generaciones podrán comprender mejor".

En Shadows and Fog (Allen, 1991) lo vuelve a decir de otra manera: "La vida no imita al arte, sino a los malos programas de televisión”. El personaje de Alvy Singer (Woody Allen) en el final de Annie Hall (Allen, 1977) comenta -después de resignarse a perder a Annie- que así deben ser las relaciones humanas, difíciles, complejas, irracionales, absurdas, pero a muchos de nosotros nos faltan las agallas. También se puede notar en el final de la icónica Manhattan (Allen, 1979) cuando el personaje de Isaac Davis (Woody Allen), después de haberse desengañado del falso amor de su alter-ego, Mary (Diane Keaton), se da cuenta que el amor honesto, pero escandaloso para la sociedad, se encuentra, en la veinte años más joven, Tracy (Mariel Hemingway), justo en el momento en que ella se va de viaje y es demasiado tarde para corresponder a su amor, al más puro estilo del final de Casablanca (Curtiz, 1942).

En todos estos personajes y secuencias de los films de Woody Allen, como dice Kierkegaard en Estadios en el Camino de la Vida (1988):

La seriedad mira a través de lo cómico, y cuanto más profundamente se alza desde abajo tanto mejor, pero no interviene. Naturalmente no considera cómico lo que quiere en serio, pero sí puede ver lo que de cómico hay en ello. De este modo lo cómico depura lo patético, viceversa, lo patético da énfasis a lo cómico. Por eso, lo más devastador sería una concepción cómica configurada de tal modo que secretamente actuase en ella la indignación, pero sin que, de pura risa, nadie la notara. (p. 366)

Es decir, lo característico de lo cómico es que algo aparece como una broma, pero oculta algo serio; es un acceso a lo serio indirectamente, digamos reflexivamente. Lo serio, en Kierkegaard, se refiere al momento en que la elección de sí mismo como posibilidad no se deriva, ni se subordina, a la necesidad de la lógica o de la naturaleza, ni siquiera a la voluntad determinada, sino que aparece con toda la fuerza de lo que ya no puede postergarse.

Un buen personaje cómico es aquél que provoca una risa sobre sí mismo para que lo serio aparezca ante nosotros, o que nos obligue a reflexionar sobre ello, como lo dice el mismo Woody Allen:

Creo que en la comedia, al igual que en una partida de ajedrez o un partido de béisbol, entran en juego mil y un elementos psicológicos conocidos y desconocidos. Si algo te hace reír es que es divertido. Es más profundo de lo que uno cree. (Lax, 2009, p. 93)

Lo cómico, así, debe tener algo patético, debe estar involucrado en un tipo especial de estado de ánimo o de un pathos especial, que nos hace compadecernos o sentirnos superiores al personaje cómico. Como sucede con el Quijote y Woody Allen: con el Quijote, sabemos que es un hombre viejo que está muriendo y con Woody Allen, debido a su fisonomía y a su manera de racionalizar todo lo que le ocurre, nos dan, ambos, la impresión de que padecen una especie de locura. La risa se despierta ya sea, porque nos sentimos superiores, por no querer caer en la demencia senil del Quijote y por no querer caer en la impotencia invaronil del personaje de Woody Allen; o ya sea, porque nos compadecemos de lo ridículo de las hazañas quijotescas y de lo absurdo que resultan las reflexiones de Woody Allen.

En lo cómico siempre brilla de alguna forma el pathos de lo trágico, porque los dos personajes nos muestran que lo real es una tragedia. El Quijote nos hace descubrir la indiferencia ante los valores más altos de la humanidad, y Woody Allen nos muestra la fragmentación y alienación del hombre moderno; por lo tanto, la falta de decisión y de pasión, ante las exigencias mismas de la existencia. El mismo Woody Allen nos ha dicho que el humor es para él un modo de invocar la inteligencia de sus espectadores, para pensar en las grandes preguntas, como le dice a Eric Lax (2009): "Solo quiero ser divertido. Y si además de eso se puede plantear una reflexión, pues mejor" (p. 93).

En Kierkegaard y Woody Allen encontramos que el humor es una forma de pensar para comprender el modo de vivir que, como dice Stephen Evans (2019), “denota la incongruencia existencial que subyace en el corazón de la lucha o el devenir religioso" (p. 89). Entonces, si bien el humor puede ser mordaz o vulgar, en Kierkegaard y Allen es la forma adecuada y artística, en que se expresa el pensador subjetivo existente, es decir, aquél que a dife- 
rencia del pensador objetivo no solo conoce en relación a la idea para llegar a conclusiones y resultados, sino que "se interesa esencialmente en su propio pensamiento y existe en él. Por consiguiente su pensamiento posee otra clase de reflexión, específicamente, aquella de la interioridad y la apropiación” (Kierkegaard, 2009, p. 74).

Para Kierkegaard el humor es un modo de la doble reflexión, esto es, que la reflexión del pensador subjetivo no se queda en el objeto sino que se remite a la relación actual y personal con su existencia en el tiempo. Esto le hace constatar que como existente está en devenir y en el fraude del devenir, el cual consiste en que el pasado no es necesario por haber sido, como dice en Migajas filosóficas (Kierkegaard, 2016). Nada se encuentra del todo claro o terminado. Las grandes interrogantes no se resuelven en teorías o resultados, sino que exigen un afrontamiento en y con el mundo.

El planteamiento de Kierkegaard, a través de Johannes Climacus, está en el mismo sentido del escepticismo de Cioran, cuando le contestó a Savater en una entrevista que no era un nihilista, sino un "escéptico que de vez en cuando había algo que lo tentaba más que la duda" (Cioran, 2004, p. 23). Woody Allen confirma estar en sintonia con ellos, cuando le comenta a Eric Lax (2009), acerca del ataque que recibió de un cura católico de promover el relativismo moral y el nihilismo con su película Crimes and Misdemeanors:

Pero eso es una conclusión equivocada. Lo que digo realmente y lo digo con toda claridad, sin ningún mensaje esotérico de por medio, es que tenemos que aceptar que vivimos en un universo sin Dios y que la vida carece de sentido y que a menudo es una experiencia terrible, brutal y sin esperanza, y que las relaciones amorosas son durísimas, y que aun así tenemos que encontrar la manera, no solo de hacer frente, sino de llevar una vida decente y moral. (...) ¿cómo podemos seguir adelante, o incluso, que razón habría para que decidiéramos seguir adelante? (...) Si uno reconoce la horrible verdad de la existencia humana y frente a ello opta por ser una persona decente en lugar de engañarse a sí mismo pensando que le espera una recompensa o un castigo divino, me parece una postura más noble. (p. 163)

Estos planteamientos podrían parecer muy negativos, y precisamente lo son, porque lo positivo, como nos dice Johannes Climacus en el Postscriptum, es lo falso existencialmente como lo son: la certeza sensible, el conocimiento histórico y el resultado especulativo (Kierkegaard, 2009). Porque el primero es un engaño, el segundo una ilusión y el tercero un fantasma, ya que ninguno de ellos remiten a cuál es el estado del sujeto que piensa en relación al devenir de su existencia. Son formas que hacen abstracción de la existencia, y pretenden cap- turarla con sus categorías, creando un sujeto ficticio que las concentre (Kierkegaard, 2009).

Como diría Paola Marrati (2006) acerca de la filosofía del cine de Deleuze, lo positivo, como falsificación de la vida, es abstraerse de la fuerza del tiempo y, en ese sentido, el pensador objetivo se hace idiota existencialmente, porque el enemigo del pensamiento no es el error, sino la estupidez, cuando se olvida de las fuerzas del tiempo, es decir, del devenir mismo (Deleuze, 1985). En cambio, el pensador negativo, nos dice Johannes Climacus, es aquel que se hace consciente de que la existencia contiene una negatividad, un devenir, que se fundamenta

en la síntesis del sujeto, en su ser espíritu infinito existente. Lo infinito y lo eterno son la única certeza, mas, dado que son en el sujeto, son asimismo en la existencia, cuya principal expresión es la equivocidad y la prodigiosa contradicción de que lo eterno deviene, de que llega a ser ahí. (Kierkegaard, 2009, p. 83)

En otras palabras, el pensador objetivo o positivo es el que omite que la existencia es una síntesis en devenir de dos ámbitos, en sí mismos incompatibles, y por ello imposibles de determinar de uno u otro modo. Solo podemos comprenderlo en la medida en que, ante la contradicción, nos atrevamos a creer que es posible una vinculación nueva que está por revelarse.

El pensamiento negativo no es una forma de pesimismo o de nihilismo, lo cual sería ya una clausura a este pensamiento, y por tanto una nueva forma de positividad falsa; más bien, es darse cuenta que en el tiempo, en lo determinado, siempre hay algo más abierto, lo infinito, que es para Climacus la única certeza. Esto mismo se encuentra en las obras de Kierkegaard como son El concepto de la angustia (2016), La enfermedad mortal (2008) y Temor y temblor (1998) con la metáfora del existente como un bailarín. La cual expresa que el sentido de la existencia no está en esos engaños, ilusiones o fantasmas de las abstracciones del yo moderno, sino en la conciencia misma de que ser yo mismo es estar abierto a algo que no soy yo como relación personal; aquello que Kierkegaard (2007) llama "lo más concreto y lo más abstracto simultáneamente: el sí mismo o la libertad” (p. 195).

La libertad se resuelve para Kierkegaard en el amor. Pero, como dice el personaje de Alvy Singer en Annie Hall (1977), nos faltan agallas para el amor, o como lo dice también Anti-Climacus, el autor seudónimo de Kierkegaard de La enfermedad mortal (Kierkegaard, 2008), nos hace falta ser valientes, esto es, creer de verdad que es posible amar.

Por ello nos dice Johannes Climacus en el Postscriptum (2009): "el pensador existente siempre contiene lo 
infinito en su alma, y por tanto, su forma es continuamente negativa” (p. 85). Esto es simultáneamente de verdad positiva, porque consiste en la interiorización del devenir en el que se hace consciente de lo negativo, sin llegar nunca a una conclusión final por una quimérica mediación (Kierkegaard, 2009).

\section{El humor en los films de Woody Allen como pensamiento subjetivo-existencial}

El humor en los films de Woody Allen es un modo de expresión del pensar subjetivo existencial, porque, como dice Johannes Climacus (Kierkegaard, 2009), éste se expresa siempre como la incertidumbre de la vida terrena en donde todo es incierto. ¿Por qué, aunque el mundo no tenga fundamento o sentido para la conciencia racional y objetiva, vale la pena elegir un modo de vida digno y con sentido?

En los films de Allen se realiza de modo fáctico lo que dice Climacus:

Aquel que existe, se encuentra constantemente en proceso de devenir, el pensador subjetivo que realmente existe, al pensar reproduce esto en su existencia e invierte todo su pensamiento en el devenir. (...) encontrarse de este modo en constante proceso de devenir es la equivocidad de lo infinito en la existencia. (Kierkegaard, 2009, p. 87)

El humor es su modo de expresión, pues como dice Climacus, el hecho de que este pensador subjetivo sea tanto positivo como negativo se puede expresar diciendo, que tiene tanto de comicidad como de pathos (Kierkegaard, 2009, p. 89). Y así, como ha explicado Stephen Evans (2019), "esta contradicción o desproporción esencial de la propia existencia, cuando la vivimos, porque la pensamos de forma negativa, puede ser trágica o cómica” (p. 89).

Lo cómico y lo trágico son las formas de expresar ese pensamiento existencial sobre la desproporción inherente a la condición del devenir existencial (Kierkegaard, 2009). Esto es lo esencial, para Kierkegaard, de ser libertad, y constituye la realidad del individuo singular como categoría fundamental de la religiosidad y del cristianismo, como lo dice en Mipunto de vista (1985).

La desproporción, esencia de lo cómico y lo trágico, como forma del humor, es en Woody Allen su reflexividad, como dice de nuevo Vittorio Hösle: "Es esta extraordinaria reflexividad la que hace a Woody tan original y fascinante, desde luego también tan desconsolado... porque la reflexividad, en esta forma especial, cierra el paso a los otros y a la vida" (Hösle, 2002, p.
60). Lo más cómico es esto, y lo más enfadoso para otros que no tienen la agudeza reflexiva, que personajes como Woody o el Quijote les exigen. Como decía Kierkegaard (2006) en "El reflejo de lo trágico antiguo en lo trágico moderno", nuestra era moderna se ha hecho extraordinariamente cómica por haber creado un sujeto fuera del tiempo y de la historia, como centro y causa, omnipotente y desapasionado, de todo lo que llega a ser. De tal forma que un individuo aislado es en realidad un sujeto que se ve en la exigencia de controlar absolutamente todas las contingencias que la vida pueda presentar, o más bien que pretende que eso sea así. La vida se ha convertido en seguir una serie de manuales, o de formatos establecidos, por sujetos no involucrados con la experiencia existencial de lo que dicen ser causa y centro. Lo cual se asemeja a la gestión cultural de nuestros días, donde los administradores o los productores no viven la experiencia creativa pero sí se dicen fuente de su sentido, pervirtiéndola completamente.

Entonces, el personaje de Woody Allen nos presenta una y otra vez la incapacidad e impotencia absolutas, de que por medio de esta reflexividad la vida pueda tener sentido. Es decir, nos muestra la parodia absoluta de este héroe moderno, o de este super individuo, o pensador objetivo y positivo, y al mismo tiempo la falta de reflexión sobre ello. Puesto que no sólo su reflexividad lo hace cómico, también el contenido de sus reflexiones son cómicas en sí mismas.

Es una crítica tanto a un tipo de reflexividad que se propone absoluta, como a la indiferencia consciente hacia las grandes preguntas. Porque, en el fondo, son indiferentes a la síntesis que es cada persona en su realidad concreta. $\mathrm{Y}$ en esta tensión reside todo su fascinante humor, porque pone a la reflexividad en su lugar, ni más allá del mundo, pero tampoco se puede vivir sin ella, su lugar está en situar al individuo ante la vida en su relación personal con su angustia y sus penas.

Por ejemplo, en el personaje femenino del film Alice (Allen, 1990), que interpreta Mia Farrow y que adquiere las características de Woody ${ }^{11}$, vemos este lugar de la reflexividad: que va pasando de la irreflexión total a la reflexión que la confunde, hasta la reflexión que la prepara para tomar una decisión. Ella ha pasado por una crisis existencial, que en un primer momento se manifiesta como un simple dolor de espalda, el cual en realidad es un síntoma de la infelicidad en su matrimonio, es decir, es irreflexiva sobre lo que realmente le pasa. Pero a fuerza de visitar al Dr. Yang (Keye Luke), medicina alternativa con tés herbales, ella va abriendo 
su reflexión sobre la realidad de su situación. Primero, perdiendo sus inhibiciones sobre sí misma, después observando con mayor claridad a quienes la rodean, y ante estos dos mundos confrontados en su interior reflexivamente tiene que decidir, pero no que decidan por ella o hacia ella, sino que debe decidir por amor a su propia vocación.

Me atrevería a decir que el humor es filosofía en este sentido del pensador subjetivo existencial, donde la verdad no está en los objetos o conceptos, sino en la apropiación en el devenir, en esa verdad que es para mí, como dice Kierkegaard (2011) en su diario. Esto se presenta como una interlocución con la alteridad de lo real, por eso no se trata ni de subjetivismo, dígase "mí verdad" o el objetivismo, dígase "en la verdad".

Es de hacerse notar como Kierkegaard y Woody Allen, convergen aún más en sus tesis, porque tanto uno como el otro vislumbran que el carácter propio de lo cómico o del pathos es que estén presentes en la misma proporción, pues como dice Johannes Climacus en el Postscriptum: lo cómico sin el pathos es inmadurez que termina en situaciones meramente absurdas y el pathos sin lo cómico es una ilusión, que termina casi siempre de modo fatal (Kierkegaard, 2009). La diferencia entre uno y otro es que: "cuando se mira la interpretación de la desproporción de la idea hacia delante, hay pathos; cuando se mira la desproporción con la idea hacia atrás, hay comicidad" (Kierkegaard, 2009, p. 91).

Cuando el pensador subjetivo se enfrenta a la idea en relación a su existencia hay patetismo, porque hay angustia, pues se abren las posibilidades infinitas más allá de donde se encuentra. Si esto no tiene una buena dosis de lo cómico, termina en neurosis, que sería una forma de la tragedia moderna. Por otro lado, lo cómico se da cuando a esa misma desproporción se le mira en retrospectiva, y le permite iluminar desde ahí su relatividad, en otras palabras, se da cuenta de la falsa seriedad de las pretensiones de sus pasiones infinitas.

En cierto modo, lo trágico moderno deviene por identificarse con la pasión de la propia voluntad sin mayor desproporción ${ }^{12}$, y lo cómico moderno cuando ella misma choca con el mundo, y la hace verse hacia atrás como futil e inútil. Lo más cómico para Kierkegaard, cuando critica el pensamiento especulativo de Hegel, es la pretensión de que podemos tener certezas sobre el futuro, cuando en realidad es imposible. Entonces, al darse cuenta de ello, es para echarse a reír de sí mismo, como cuando Woody Allen dice "Quieres hacer reír a Dios, cuéntale tus planes futuros”.
La tragedia y la comedia, cuya síntesis es el humor, son dos modos de ver el mismo devenir de la síntesis humana con la verdadera seriedad, y por ello a través de lo cómico se ve lo serio, pues como nos dice Johannes Climacus en el Postscriptum: "posee tanto patetismo como comicidad: patetismo debido a que la lucha es infinita, es decir, apunta hacia lo infinito, es un proceso de eternización, lo cual representa el más alto pathos; comicidad porque la lucha es una autocontradicción" (Kierkegaard, 2009, p. 93). En este sentido, el humor termina siempre siendo un modo de abrirse a una relación que nos trasciende, y nos pone en disposición, probablemente esta sea su diferencia -que quedaría para otro trabajo- con la ironía, pues ésta más bien desengaña en la propia inmanencia, pero no dispone, porque el humor es presencia de la auto-contradicción de las pasiones del infinito.

Los filmes de Woody Allen se han desarrollado como la construcción de imágenes que sean síntesis de comedia y tragedia. Como lo ha comentado Sam B. Girgus (2013), el humor de Allen parece una combinación de la idea de "divina comedia" de Levinas, que sugiere la presencia del poder del infinito en el corazón de la experiencia humana, y de la idea de Julia Kristeva, de la construcción del sujeto ético en el lenguaje, como encuentro con su alteridad. Es decir, los filmes aparecen como la propuesta de la apertura de una brecha que sugiere la infinitud del deseo, el amor y el lenguaje.

Esto concuerda con la idea del humor en Kierkegaard, como la forma de ser del pensador subjetivo ético-existencial. Porque el pensar produce su propia apertura a una realidad infinita de la relación con el otro, por lo cual es posible darle a la creencia, como forma de la elección, el lugar que le corresponde en su relación y responsabilidad de enlazarse de nuevo con el mundo, dicho de otro modo, para recibir el mundo con una mirada nueva. Girgus (2013) concluye que los films de Allen pueden ser considerados "como un arte que mira al abismo, pero que abre la posibilidad de una ética trascendente" (p. 571).

Esto refuerza la idea de que tanto en Kierkegaard como en Woody Allen el humor no tiene solo una función de divertimento o de entretenimiento, ni siquiera de la sola relativización de un argumento. En ambos el humor hace aparecer el sentido de la seriedad, como la responsabilidad ética de cada individuo de asumir honestamente su condición existencial, y como apertura al infinito y al otro desde sí mismo. El humor, particularmente en Woody Allen, como forma cinematográfica, 
tiene un sentido filosófico, como ha dicho Lou Ascione (2004):

usando el humor para resaltar las incongruencias del comportamiento humano, él es capaz de hacer comentarios críticos, así como señalar preguntas filosóficas importantes acerca de temas sociales y culturales. (...) Woody Allen es uno de los pocos capaces de producir humor tanto para fines de entretenimiento como filosóficos. (pp. 149-150).

Como ilustración filmica de esta idea del humor, como integridad proporcional y dinámica, no cerrada, entre lo tágico y lo cómico -que es a la vez la forma del pensador subjetivo en Kierkegaard, y la forma del pensamiento filosófico cinemático de Woody Allen- si bien podría hacerse en particular en cada uno de sus fil$\mathrm{ms}$, aparece como planteamiento explícito en el film de 2004 de Allen: Melinda and Melinda. En éste, de forma analóga al texto de Kierkegaard En la espera de la fe (2005), unos amigos escritores se juntan para discutir si la existencia es trágica o cómica-siendo que uno de ellos, Max (Larry Pine) es escritor de tragedias y el otro, Sy (Wallace Shawn) de comedias- y el film consiste en ver cinemáticamente la misma historia, en sus dos versiones, desde la perspectiva solo de lo trágico, y la otra solo de lo cómico, protagonizadas por el mismo personaje de $\mathrm{Me}$ linda (Radha Mitchell).

\section{Melinda and Melinda (Allen, 2004): ¿Por qué la existencia no es ni trágica ni cómica?}

En el film Melinda and Melinda, desde la primera escena se nos plantea la pregunta filosófica fundamental sobre la relación entre la realidad y el humor, desde su aspecto trágico o cómico, que ilustra lo que hemos venido exponiendo: que la existencia no es ni trágica ni cómica, sino una relación recíproca y proporcional entre ellas de forma dinámica, en donde lo que media es la libertad. Pero, además, el film nos hace ver que si solo identificamos lo real con lo trágico o con lo cómico, se vuelve una distorsión tanto para la existencia, como para la pretensión de verosimilitud y de pensamiento del arte de la escritura o de la cinematografía. Asimismo, la narrativa plantea que quedarse solo en lo trágico degenera la vida en fatalidad o neurosis, y quedarse solo en lo cómico la precipita hacia la locura o lo rídiculo, por lo que el arte de escribir adquiere tal relatividad de argumentos sobre su verosimilitud que no hay forma de definir desde qué aspecto, trágico o cómico, la realidad se representa mejor.

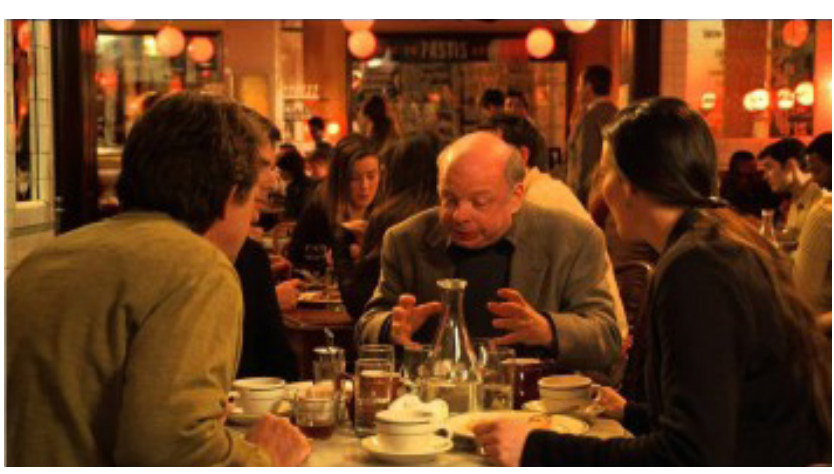

En esta primera escena, vemos a dos parejas de amigos escritores, Max, dedicado a escribir tragedias y dramas, y Sy, dedicado a la comedia, discutiendo si la realidad es esencialmente cómica o trágica. Lo interesante de la secuencia es que ninguno defiende el aspecto de su propia escritura como la real, sino justo la contraria. Para Max la realidad es esencialmente cómica porque es absurda, ya que si fuera trágica, entonces sus obras se venderían más que las cómicas. Pero Sy defiende que la realidad es esencialmente trágica, y dado que la comedia es un escape a la misma, las personas compran las trágicas porque las situan en lo real. Para decidir sobre el argumento, el film de Allen nos presenta la historia del personaje Melinda como historia trágica y cómica simultáneamente, en lugares, espacios, tiempos o mundos paralelos.

Lo que las historias de ambas Melindas nos muestran es que la realidad no es ni trágica ni cómica esencialmente, sino que ambas son formas de comprender la verdad que escapa a un sistema lógico de pensamiento, expresando que la realidad es más compleja que lo que parece, abriendo el pensamiento y la libertad a su disposición. Es decir, la tragedia y la comedia no agotan la realidad, sino que evidencian la condición de apertura infinita de la misma, como hemos expresado, en cuanto al carácter del pensador subjetivo existencial de Kierkegaard.

En el film de Allen se hace patente que tanto la tragedia como la comedia manifiestan una incongruencia o una desproporción entre la interioridad y la exterioridad, entre el pensar y el ser, entre el actuar y el decir, en donde se abre el misterio de lo real y de la libertad. La libertad entendida como la elección y la disposición a la novedad de lo real, aniquilando la pretensión de la objetivación o de la determinación del sujeto moderno, como hemos expuesto anteriormente.

La tragedia hace que la realidad acontezca de modo directo y emerja de su ocultamiento. En el caso de la 
historia de la Melinda trágica ${ }^{13}$, su neurosis será una forma de ocultar su conciencia de esta condición existencial. En ella podemos ver lo que dice Kierkegaard (2006) en su texto "El reflejo de lo trágico antiguo en lo trágico moderno" (pp. 163-164), acerca de cómo la fatalidad de lo irremediable, se traslada del cosmos a la subjetividad, en la forma de una pasión fundamental como es la pena.

La Melinda trágica carga una pena que consiste en la incomprensión de los actos -incluyendo un asesinato- que la han llevado a dejar de ser la que siempre soñó, cuando era una joven universitaria. Su vida pasó de ser la joven deseada, atractiva y sofisticada, a establecerse como una esposa que materialmente lo tenía todo. Ella tira esta vida al abismo, y produce el asesinato, por un amor romántico y peligroso, pero sin ninguna continuidad, quedándose en el estado actual con su pena y sin amor.

La pena se delata como un círculo que intentaba recuperar algo que había perdido, por lo que su tragedia en realidad no es el asesinato, sino que tanto el asesinato y el aburrimiento de esa vida, son signos de una pérdida más fundamental: la de sí misma. Eso se muestra en el personaje por la neurosis, la inquietud y el modo de vestir, tanto que cuando cree que encuentra una persona que la salvará, porque le ha confesado su pena, Ellis Moonsong (Chiwetel Eijofor), la ironía es que él está en realidad enamorado de su tímida amiga Laurel (Chloë Sevigny), la que parecía ser la menos atractiva del grupo. La culpa y la pena se repiten, convirtiéndose en algo insoportable que termina haciéndola colapsar nerviosamente.

La tragedia se expresa en la modernidad, como se ve en la Melinda trágica, como una escalada de la angustia en una pasión insondable. De hecho, si bien ambas Melindas aparecen de improviso en escena, ésta hace evidente que el matrimonio de su amiga Laurel -que es la anfitriona de la cena donde aparece- con el joven actor Lee (Jonny Lee Miller), no funciona. Laurel se da cuenta de la tragedia de su propia relación matrimonial, ya que siendo la chica tímida del grupo de amigas, y Melinda siendo la chica seductora, termina casándose con el "chico bonito" y deseado, no por amor, sino porque de las tres ella se consideraba la menos afortunada. Por ello, mientras tanto, la tercera amiga del grupo, Cassie (Brooke Smith), casada con un profesional del derecho y embarazada, tenía una aventura con el esposo de Laurel, sintiéndose con una cierta superioridad y envidia sobre Melinda, al verla arruinada como persona en su situación vital.
La tragedia es como en Las penas del joven Werther de Goethe, la de no poder ser sí misma, y no comprenderse a sí misma. Lo cual se denota en su angustia, su ambivalencia, sus pasiones, y la imposibilidad de relacionarse consigo misma. Esto se ve en el film, sobre todo en tres secuencias: primero, cuando llega de improviso a la cena de sus amigos, segundo cuando confiesa el secreto de su pena, pero sin revelar la verdad, y tercero cuando confiesa el asesinato frente a Ellis Moonsong. A través de cada una de estas escenas el motivo de la tragedia se va haciendo patente, ella lo va haciendo público, pero lo trágico se da porque no hay forma de resolver el lazo que ha perdido, ya que toma el falso camino de creer que esto sería resuelto por transferir sus culpas al encuentro de otro ser amado, desligando la proporción adecuada que podría haber tenido con lo cómico.

En la primera secuencia, la de su llegada -aproximadamente del minuto 7 al 8:45-, expresa una falsa seguridad; aunque los personajes de la cena son sus viejos amigos, no se siente en confianza para abrirse a ellos. Su cabello, ropas y fisonomía, en general, se muestran descuidados y desaliñados, lo cual se refuerza con el cigarrillo que fuma para evitar las relaciones o confrontaciones. Esto se remata con el comentario de todos ellos, cuando Melinda no está presente, haciendo alusión a que literalmente no la reconocen.

En la segunda secuencia -aproximadamente del minuto 15:54 al 18:17-, una vez que los amigos de Melinda, el matrimonio de Laurel y Lee, le han dado un cuarto para quedarse a dormir -mientras resuelve sus asuntos desconocidos- ella se siente obligada a confesarles el secreto de sus penas, aparentemente con madurez y soltura. Pero la historia que cuenta no es completa, ni sincera, porque se expresa como si ella fuera una víctima de las circunstancias -que fueron producidas por una contradicción existencial, ante la cual tomó una mala decisión, mereciéndose estar en la posición actual.

Melinda expresa una contradicción evidente entre el motivo real de su pena y de su culpa con sus palabras, su expresión facial y corporal. Se acentúa por el encuadre, que inicia con un plano casi general de Melinda hasta llegar a un primer plano de su rostro. Movimiento de cámara que avanza con ciertas pausas que denotan las dudas interiores de Melinda, o que subrayan los momentos en donde lo que dice no es lo que en realidad sucedió o está sintiendo. Aparentemente Melinda se asume como responsable total de la situación, pero hay algo que no está del todo claro y que no encaja en lo que dice, por lo cual es una falsa asunción de la culpa que la llevó a este momento. 


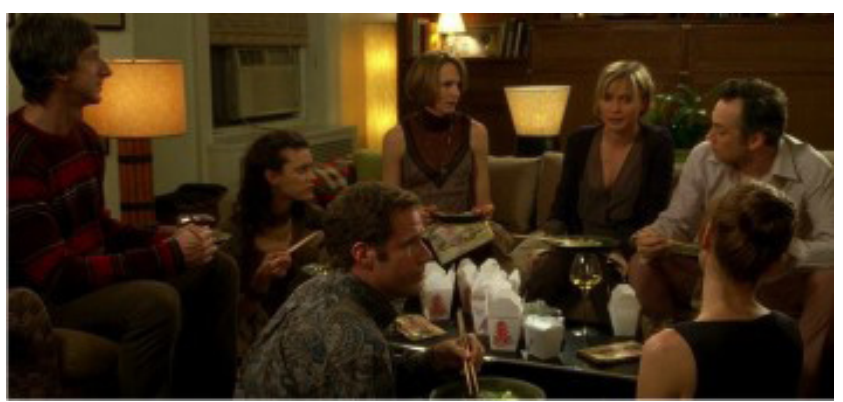

Lo que no encaja tiene dos momentos: el primero, al decir que dejó a su maravillosa familia por el hecho de sentir que no era una vida para ella, por lo cual era una aburrición existencial. Al parecer es su primera culpa, la de haber elegido un modo de vida que no iba con su forma de ser. Y segundo, cuando expresa que los dejó por una aventura amorosa con el Sr. Giuliano, romántico, exótico, que al final del día la abandonó como a una más, y por tanto se quedó sin familia y sin amor romántico. Pero este final de la historia, lo cuenta de forma tan abrupta, entre el modo de referirse al Sr. Giuliano, la mirada, y el primer plano de la cámara, deteniéndose dubitativamente, que se hace evidente que entre la aventura y el término de la relación hay algo que no se está diciendo.

Hasta este momento tenemos una escalada de la pena trágica, pues la conciencia de sus propios actos y de su historia, no la han llevado a recapacitar, a asumirla, o a tomar un curso de acción distinto, si no a proseguir en un estado de indiferencia activa, donde su angustia parece haber crecido en relación a los posibles no resueltos del pasado, haciendo exponencial la incomprensión de su propia culpa y más profunda su pena.

Finalmente, la tercera secuencia aproximadamente en el minuto 55, después de que aparentemente ella se ha enamorado y ha sido correspondida por el personaje de Ellis Moonsong -lo cual inclusive hace que su forma física se denote con mayor cuidado de sí- se siente obligada por el amor a confesar el secreto oculto: que ella mató al Sr. Giuliano a propósito por despecho. Lo cuenta detalladamente, así como la forma en que evitó la justicia, la premeditación, las mentiras en el juicio, la cárcel y su intento de suicidio.

La cámara filma la secuencia comenzando con un primer plano, en donde Melinda inicia su confesión, continua a un plano general que la sigue en su cambio de posición, quedando a media espalda hacia Ellis Moonsong, y finaliza en un medio plano. Al contrario de la primera secuencia, la cámara se queda en este momento fija, casi como una imagen petrificada, con la misma frialdad con que ella cuenta la historia, sin dudas ni matices, indican- do que se está describiendo la cruda verdad, por decirlo de esta forma. Sin embargo, la esperanza de Melinda es que la verdad y la honestidad ante un hombre con el que sí está enamorada restituirán su culpa y la liberarán de la pena. Pero, su tragedia termina por expresarse como fatalidad subjetiva, porque Moonsong en realidad está enamorado de Laurel, por lo que a Melinda se le hace absolutamente incomprensible en la lógica como ella ha ordenado los eventos.

Visto desde la perspectiva de Kierkegaard en el Postscriptum, cada una de las confesiones de Melinda eran pretensiones lógicas de enunciación para determinar el curso necesario de su pasión, y al no realizarse, al evidenciarse que es inconsecuente, se vuelve insoportable, colapsando psíquicamente. La fatalidad no es que Moonsong se enamorara de su amiga, sino que la lógica de las pretensiones de su pasión no se lograra, porque la realidad las trascendía, y eso no lo podía aceptar, para ello le hubiera faltado el aspecto cómico.

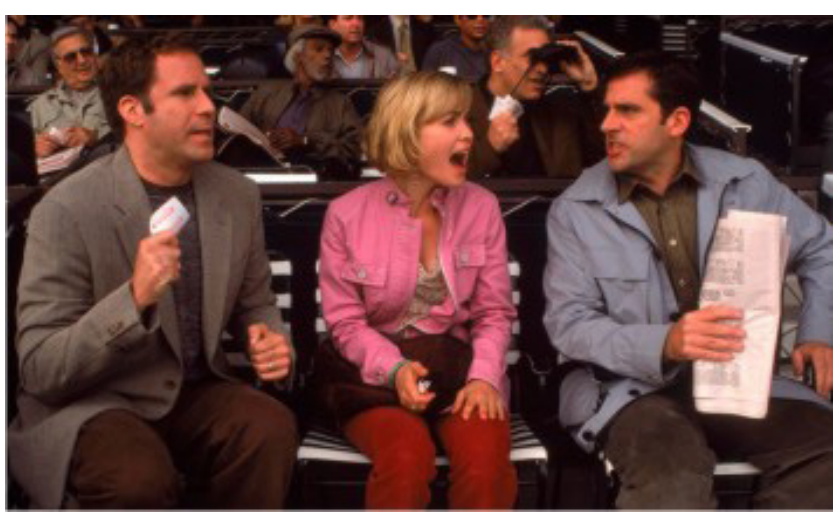

Si la tragedia confronta, la comedia es una relación indirecta con la verdad. Por eso, desde una perspectiva superficial, parece evasión, pero, más bien, se abre a una mayor conciencia de la propia condición, cuando equilibra el sentido trágico convirtiéndose en humor, en donde la elección se denota con su infinitud interior. Porque el humor nos presenta con una verdad nueva, desconocida, pero presente como un horizonte de posibilidades.

Esta es la diferencia con la ironía, que nos hace reconocer la verdad como es, nos des-engaña de cómo creíamos que era. Ambas indican la verdad pero, en sentidos inversos. El ironista, como Sócrates (Kierkegaard, 2000), se mueve en el ámbito de las verdades que están a disposición de los seres humanos, y el humor hace posible moverse en un ámbito de verdades trascendentes. Porque la novedad de la verdad es radical, es decir, que no se deriva del esquema lógico, o de la necesidad natural, o de lo razonable, por eso en la comedia impera siempre la sorpresa. 
La ironía parte de algo que parece muy serio, es decir, de estar conforme con la verdad como se encuentra en el mundo percibida, justificada, etc. Pero, en realidad es una broma, en el sentido de hacer aparecer que no es toda la verdad, ni del modo como se concebía, sino que hay que investigar de modo más profundo. La ironía nos hace así reconocer la propia ignorancia de nuestros fundamentos y nos desengaña.

El humor va en sentido inverso a la ironía con el mismo fin, porque hace aparecer algo como una broma, pero en realidad es una verdad nueva, que es muy seria; y que no se encuentra en el modo como la percibíamos, o la comprendíamos, sino que requiere una disposición a comprenderla de un modo radicalmente diferente. Por eso el humor nos abre a conocer una verdad no posible de conocer hasta ese momento.

Desde esta perspectiva, en la historia de la Melinda cómica, el rol de la Melinda trágica se transfiere al personaje de Hobie (Will Ferrell), quien es absurdo y ridículo, porque se oculta a sí mismo, y el humor como equilibrio del patetismo cómico, lo hace reconocer constantemente que no sabe cuál es esa verdad que le corresponde.

La llegada de Melinda hace que Hobie se encamine por el sendero de reconocer el absurdo de su vida matrimonial, porque está casado de forma convencional con una mujer profesionista que lo humilla en cada oportunidad que tiene. Su absurdo se manifiesta por ser un actor profesional desempleado cuya mejor actuación es cocinar. Entonces, esto parece una broma, pero nos señala las incongruencias que se ocultan por su propia condición existencial.

La principal diferencia entre la historia de comedia con la tragedia, es que todo lo que le sucede al personaje de Hobie, sea extraordinario, humillante o trágico, pierde relevancia ante la mirada en retrospectiva de su propia situación y condición humana. Es decir, nada es tan extraordinario, ni tan humillante, ni tan trágico, por lo que valga la pena cambiar de vida. Esto lo va haciendo consciente de la incongruencia de su forma de ser y su interioridad, es decir, de su condición trágica y patética. Conciencia, que sin embargo no termina en decepción o resignación, sino en un final típico de una comedia romántica ligera. Una vez que Hobie ha aceptado que Melinda no lo va a amar, ella se da cuenta casi de sorpresa, de que sí está enamorada de él, tan asombrada de sí misma como Hobie de la situación, por lo que lo trágico se detiene en sus pretensiones de fatalidad y Hobie cree de verdad que es posible.

Todo ello se da en la secuencia final, en la que el sueño y la realidad se confunden. La escena expresa una su- puesta relación de Hobie con una Femme Fatale, que no tiene ningún sentido, ni lo lleva a ninguna parte. Pues en esta secuencia la mujer seductora termina queriendo tirarse de la ventana, lo cual la hace absolutamente ridícula, pues lo lógico-trágico sería que el desamorado de Hobie fuera el suicida. Es en ese momento cuando despierta del sueño, o ¿ de la realidad?, por lo absurdo de sus falsas pretensiones.

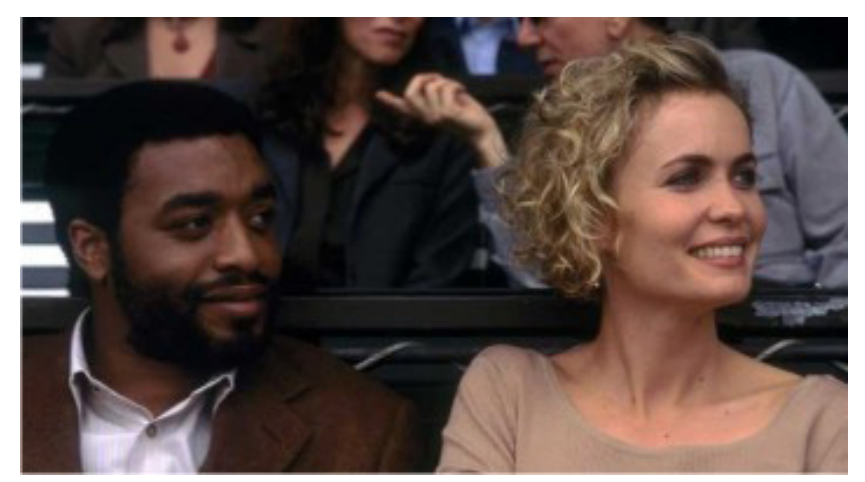

De algún modo, lo cómico, diría Kierkegaard, relativiza las falsas pretensiones de la lógica de nuestras pasiones. Esto es lo absurdo del sueño, y permite que las personas se abran a lo que la realidad tiene que ofrecer, que en este caso sea que, sorpresivamente, Melinda aparezca en la puerta de la casa de Hobie y le confiese su amor.

Al final del film, regresamos a la mesa donde cenan los amigos escritores del inicio, donde es el humor el que impera como la trascendencia de ambos aspectos hacia una forma de gozar de la vida, lo cual puede interpretarse como estar dispuestos a posibilidades nuevas, como lo dice el personaje de Sy:

Los momentos de bumor existen. Yo los exploto. Pero existen dentro de un marco general trágico. (...) Nos reímos porque eso oculta nuestro terror a la mortalidad (...) ¿Cómo puede ser un mundo romántico, chistoso, si los cardiogramas no sirven? (...) Cómica o trágica, lo importante es disfrutar de la vida mientras puedes. Solo vivimos una vez y cuando se acaba, se acabó. $Y$, aunque tu cardiograma esté perfecto, se puede acabar de repente, asi (Allen, 2004).

Acto seguido, Sy choca los dedos, y la película termina con un fundido en negro.

\section{Conclusión}

Como nos dice Lou Ascione (2004), el humor señala las incongruencias entre situaciones esperadas y su realidad, entre la interioridad y la exterioridad. Por lo cual, el humor tiene un valor filosófico en dos sentidos: primero, 
porque al mostrar esas incongruencias hace posible que se pueda entrar a tener una comprensión sobre cuestiones que de otro modo presentadas no se accedería; y segundo, porque el humor tiene una cierta inmunidad crítica que permite reflexionar sobre los temas. Por ello, la comedia expresa de modo indirecto la tragedia de la vida, y la tragedia es una expresión de lo cómico de la existencia.

Tanto la tragedia como la comedia hacen aparecer la infinitud de la interioridad, y su mayor desproporción con el mundo en el que se encuentran. Por eso la tragedia y el humor aparecen con mayor fuerza en ámbitos de crisis o en cambios de época, o marcan cambios de época, a nivel social, individual o de pareja. Porque relativizan las falsas pretensiones o seriedades en todos los sentidos, y nos abren, nos disponen, a elegir recibirnos, es decir, al final son modos de concebir la lucha del amor, que es lo serio de verdad.

Esto es en lo que consiste el devenir de la existencia, como dice Johannes Climacus, porque es el hijo concebido de lo finito y lo infinito, lo eterno y lo temporal, que se encuentra en constante lucha. Comedia y tragedia, nos expresan, tanto en Kierkegaard como en Woody Allen, en el creyente y el escéptico, que el sentido se encuentra en luchar por ese estado de apertura en el que se tiene la disposición al amor, no como lo que nuestra pasión o voluntad desean, quieren o imponen, sino como el deseo de esperar en la realidad misma, equilibrando nuestras pretensiones por la relativización de lo cómico y a la inversa, equilibrando la relativización cómica por la dirección de una pasión, como nos dice Climacus: "el amor se halla en constante lucha, esto es, el sujeto pensante se encuentra existiendo" (Kierkegaard, 2009, p. 94).

Este devenir solo puede pensarse si de algún modo los ámbitos de lo trágico y lo cómico no se identifican con lo real, sino que cumplen con su función de hacer evidente el proceso del devenir existencial que requiere trascender tanto lo férreo y determinado de la pasión, el deseo y la voluntad, como la relativización de todo lo que acontece. Dando pautas para que exista una apertura suficiente de relación libre, y dispuesta de la persona con lo real, es decir, de un modo de pensamiento subjetivo existencial, que no se remite, ni se reduce a las conclusiones, sino a las relaciones entre su pensar, su condición y su acontecer; eligiendo el vínculo como la relación, que al mismo tiempo es determinación y espera, lo cual constituye, como síntesis dinámica, el sentido del humor.

Los filmes de Woody Allen presentan esta forma del humor en las formas del movimiento y el tiempo del cine.
Ellas le dan al humor, al equilibrio entre lo trágico y lo cómico, su experiencia real, porque son formas de devenir. Es decir, la filosofía del humor cinemática de Woody Allen como forma del pensador subjetivo existencial de Kierkegaard, independientemente de las formas y los temas, produce las posibilidades de la espera dinámica de una elección, de ese vínculo ante la conciencia, inclusive de la objetividad fría de la realidad, o de las relaciones humanas con sus dificultades.

El tema es que la existencia, ante la pura conciencia objetiva, aparece siempre como un sinsentido, y cuando se quiere derivar de ella, de sus conclusiones, subordinándose a la estructura de un yo moderno, se falsea el devenir, porque se piensa que el pasado o el tiempo tienen el mismo carácter de necesidad que la lógica. Esto es lo que el humor denota, y nos ayuda a pensar, que ni el pasado es necesario por serlo, ni el futuro por quererlo, y pone en su justo lugar a la pasión del futuro, que sin lo cómico es fatalidad.

El humor relativiza la necesidad del pasado que sin lo trágico se vuelve irrelevante. Nos pone en el centro del debate del devenir, y de asumir una responsabilidad de elegir. El humor es una forma de la creencia en este mundo, y de los vínculos entre sus propios virtuales y posibilidades, lo cual es el sentido esencial de la vida ética.

El humor hace que el tiempo aparezca con su propia potencia, y a la vez como la vida del pensamiento. Por ello, la mejor forma de comprenderlo o demostrarlo es la cinematografia, porque su objeto propio es presentar este fraude del devenir en su acontecer.

El humor es un ámbito de encuentro para creyentes y no creyentes, por lo que al final lo mejor que podemos desear para que la vida tenga sentido éticamente es que la risa esté de nuestro lado, como nos dice el autor seudónimo de Kierkegaard al final del Diapsálmata en la primera parte de $O$ lo uno o lo otro. Un fragmento de Vida I (2006):

Algo fantástico me ha sucedido. Fui arrobado en el séptimo cielo. Allí se encontraban reunidos todos los dioses. Por su excepcional misericordia me fue concedida la gracia de formular un deseo. (...) Permanecí indeciso un instante, pero me dirigí en seguida a los dioses de este modo: Muy estimados contemporáneos, solo escojo una cosa, tener siempre la risa de mi parte. No hubo ni un dios que respondiese una palabra; en cambio, todos ellos se echaron a reír. De ello deduje que mi súplica había sido atendida y encontré que los dioses habían mostrado buen gusto al manifestarse, pues habría sido impropio responder con seriedad: «Séate concedido». (p. 66) 


\section{Referencias}

Allen, W. y Taniguchi, S. (directores). (1966). What's Up, Tiger Lily?. [Lily la tigresa]. [película]. American International Productions; Toho Benedict Pctures Corp.; National Recording Studios.

Allen, W. (director). (1969). Take the Money and Run. [Robó, huyó y lo pescaron] [película]. ABC, Palmoar Pictures International. Allen, W. (director). (1971). Bananas. [La locura está de moda] [película]. United Artists.

Allen, W. (director). (1975). Love and Death. [Amor y Muerte: La última noche de Boris Grushenko] [película]. United Artists. Allen, W. (director). (1977). Annie Hall [Dos extraños amantes] [película]. United Artists.

Allen, W. (director). (1978). Interiors [Interiores] [película]. United Artists.

Allen, W. (director). (1979). Manhattan [película]. United Artists.

Allen, W. (director). (1986). Hannah and Her Sisters [Hannah y sus hermanas] [película]. Orion Pictures.

Allen, W. (director). (1989). Stardust Memories [Recuerdos] [película]. United Artists.

Allen, W. (director). (1989b). Crimes and Misdemeanors [Crímenes y pecados]. [película]. Orion Pictures.

Allen, W. (director). (1990). Alice [película]. Orion Pictures.

Allen, W. (director). (1991). Shadows and Fog [Sombras y niebla] [película]. Orion Pictures.

Allen, W. (1997). Cuentos sin plumas. Tusquets.

Allen, W. (director). (2004). Melinda and Melinda [Melinda y Melinda] [película]. 20th Century Fox; Fox Searchlight; Perdido Productions; Gravier Productions.

Allen, W. (2011). Introduction. En Ingmar Bergman (Ed.) Images. My Life in Film. Arcade Publishing.

Allen, W. (director). (2015). Irrational Man [Un hombre irracional] [película]. Sony Picture Classics; Gravier Productions.

Allen, W. (2020). A propósito de nada. Autobiografía. Alianza editorial.

Ascione, L. (2004). Dead sharks and Dynamite Ham: The Philosophical Use of Humor in Annie Hall. En Mark T. Conrad y Aeon J. Skoble (Coords.) Woody Allen and Philosophy. (pp. 132-150). Open Court.

Bailey, P. J. (2013). Introduction. En Peter J. Bailey y Sam B. Girgus (Eds.) A Companion to Woody Allen. (pp. 1-12). John Wiley $\&$ Sons.

Brigham, W. (2019). Historical Dictionary of Woody Allen. Rowman \& Littlefield.

Camus, A. (2002). El mito de Sísifo. Alianza editorial.

Cioran, E. M. (2004). Breviario de podredumbre. Una tormenta de lucidez. Suma de letras.

Cioran, E. M. (2010). Ese maldito yo. Tusquets.

Curtiz, M. (director). (1942). Casablanca [película]. Warner Bros.

Detmer, D. (2013). The Philosopher as Filmmaker. En Peter J. Bailey y Sam B. Girgus (Eds.) A Companion to Woody Allen. (pp. 460-480). John Wiley \& Sons.

Deleuze, G. (1985) La imagen-tiempo. Estudios sobre cine 2. Paidós.

Donner, C. (director). (1965). What's New Pussycat? [¿Qué pasa pussycat?] [película]. United Artists.

Evans, S. C. (1987). Kierkegaard's view of humor. Must Christians always be solemn? Faith and Philosophy, 4(2), pp. 184-185.

Evans, S. C. (2019). Kierkegaard and Spirituality. Accountability as the Meaning of Human Existence. Eeerdemans.

Fellini, F. (director). (1963). 8 1⁄2. [película]. Cineriz, Francinex.

Girgus, S. B. (2013). Afterword. The Abyss: Woody Allen on Love, Death and God. En Peter J. Bailey y Sam B. Girgus (Eds.) A Companion to Woody Allen. (pp. 559- 572). John Wiley \& Sons.

Guest, V. (director). (1967). Casino Royale. [película]. Famous artists Productions, Columbia Pictures.

Hischak, T. S. (2018). The Woody Allen Encyclopedia. Rowman \& Littelfield.

Hösle, V. (2002). Woody Allen. Filosofía del bumor. Tusquets.

Kierkegaard, S. (1985). Mi punto de vista. (trad. José Miguel Velloso). SARPE.

Kierkegaard, S. (1988). Stages on Lifes Way. (trad. Howard and Edna Hong). Princeton.

Kierkegaard, S. (1998). Temor y temblor. (trad. Vicente Simón Merchán). Técnos. 
Kierkegaard, S. (2000). De los papeles de alguien que todavía vive. Sobre el concepto de ironía. (trad. Darío González y Begonya Saez Tajafuerce). Trotta.

Kierkegaard, S. (2005). En la espera de la fe. Todo don bueno y toda dádiva perfecta viene de lo alto. (trad. Leticia Valádez). Universidad Iberoamericana.

Kierkegaard, S. (2006). O lo uno o lo otro. Un fragmento de vida I. (trad. Darío González Begonya Saéz Tajafuerce). Trotta.

Kierkegaard, S. (2007). O lo uno o lo otro. Un fragmento de vida II. (trad. Darío González). Trotta.

Kierkegaard, S. (2007b) Johannes Climacus o el dudar de todas las cosas. (trad. Patricia Carina Dip). Editorial Gorla.

Kierkegaard, S. (2008). La enfermedad mortal. (trad. Demetrio Gutiérrez Rivero). Trotta.

Kierkegaard, S. (2009). Postscriptum no científico y definitivo a Migajas filosóficas. (trad. Nassim Bravo). Universidad Iberoamericana.

Kierkegaard, S. (2011). Los primeros diarios. Volumen I. 1834-1837. Universidad Iberoamericana.

Kierkegaard, S. (2016). Migajas filosóficas. El concepto de la angustia. Prólogos. (trad. Darío González). Trotta.

Lax, E. (2009). Conversaciones con Woody Allen. Lumen.

Lee, S. H. (1997). Woody Allen's Angst. Philosophical Commentaries on His Serious Films. Mc Farland \& Company, Inc.

Marrati, P. (2006). Gilles Deleuze. Cine y filosofía. Nueva Visión.

Sayad, C. (2013). The Stand-up Auteur. En Peter J. Bailey y Sam B. Girgus (Eds.) A Companion to Woody Allen. (pp. 15-34). John Wiley \& Sons.

South, J. B. (2004). “You Don't Deserve Cole Porter”: Love and Music According to Woody Allen. En Mark T. Conard y Aeon T. Skoble (Eds.). Woody Allen and Philosophy. (pp. 118-131). Open Court.

1 Véase el recuento de la obra de Allen que hacen Peter J. Bailey en la introducción de A Companion to Woody Allen (2013, pp. 4-8).

2 En general se considera el filme Take the Money and Run (Allen, 1969) como el primer filme de Allen en donde tiene pleno control de la escritura y la dirección, y a partir del cual realizará en promedio un filme por año hasta el momento. Antes de ella el director neoyorquino escribió el guion de la fallida comedia What's New Pussycat? (Donner, 1965), dirigió el re-make de una película de serie B japonesa What's up Tiger Lily? (Allen, 1966), y actúo en la sátira de James Bond Casino Royale (Val Guest et.al., 1967).

3 Cecilia Sayad (2013) discute la idea de Woody Allen como autor cinemático en varias dimensiones, pero remarca dos aspectos de su autoría: primero, su evolución de las comedias populares a temas más filosóficos y preguntas metafísicas; segundo, las tensiones de las interdependencias entre el arte y la autoría individual de Allen dentro de la cultura fílmica de Estados Unidos (American Film Culture). Esto también se puede notar por los libros de tipo diccionario o enciclopédico que han aparecido en los últimos años sobre la obra de Woody Allen como Historical Dictionary of Woody Allen de William Brigham (2019) o The Woody Allen Encyclopedia de Thomas S. Hischak (2018).

4 Por dar dos ejemplos en sus filmes véase en Irrational Man (Allen, 2015) la secuencia y el eje narrativo que define al personaje de Abe Lucas (Joaquin Phoenix) en torno a la obra de Los Hermanos Karamazov sobre el crimen perfecto, como el único acto moralmente auténtico. O en Love and Death (Allen, 1975) que está construida sobre las ideas, ambientes, palabras de las obras de Tolstoi y Dostoievsky.

5 Las referencias a Ingmar Bergman no sólo aparecen explícitamente en filmes como Manhattan (Allen, 1979), sino que Allen ha mencionado su admiración y devoción por el director sueco en sus entrevistas (Lax, 2009, p. 94, p. 166, pp. 323-324) ha hecho algunos filmes con un claro estilo Bergman como Interiors (Allen, 1978), trabajado con su cinefotógrafo Sven Nykvist, tenido como actor a Max Von Sydow, quien fuera uno de los principales actores de los filmes de Bergman e inclusive escribió la introducción a su autobiografía Images. My Life in Film (Allen, 2011). Por otro lado, Stardust Memories (Allen, 1980) se puede decir que es la versión del neoyorquino de 8 1/2 (Fellini, 1963).

$6 \quad$ Por dar tres ejemplos de referencias explícitas a Kierkegaard véase en Bananas (Allen, 1971) la secuencia donde el personaje de Fielding Mellish (Woody Allen) cita a Kierkegaard para hacerse el interesante con una chica típica pseudo-intelectual de la década de los 70; en Manhattan (Allen, 1971) la famosa secuencia donde el personaje de Mary (Diane Keaton) califica los programas de televisión de Isaac (Woody Allen) con ese tono del silencio de Dios y en Irrational Man (Allen, 2015) donde el personaje de Abe Lucas (Joaquin Phoenix) explica la angustia como vértigo de la libertad, y no sin mencionar la referencia al inicio de este trabajo de su texto Cuentos sin plumas (Allen, 1997).

7 Véase el libro Woody Allen and Philosophy (Conard \& Skoble, 2004) en particular el texto de James B. South (2004) "You Don't Deserve Cole Porter”: Love and Music According to Woody Allen” (pp. 118-131); el texto de Sander H. Lee (1997) Woody Allen's Angst. Philosophical Commentaries on His Serious Films, en particular el capítulo 4 "Themes of Redemption: Manhattan (1979)" (pp. 86-111); en cuanto a la filosofía del humor el texto de Vittorio Hösle (2002) o el texto de David Detmer (2013) sobre Woody Allen como filósofo-cineasta. 
8 El salto cualitativo es una categoría desarrollada por Kierkegaard en varias de sus obras y que en general se podría plantear como la elección entre querer creer o no en el elegir mismo, como lo tematiza en O lo uno o lo otro. Un fragmento de vida II: "No por ello se trata todavía de elegir alguna cosa, no se trata de la realidad de lo elegido, sino de la realidad del elegir” (Kierkegaard, 2007, p. 164); o es como la forma de la elección que se encuentra ante la paradoja absoluta y tiene dos posibilidades, o el escándalo, o la fe, en Migajas filosóficas (Kierkegaard, 2016, p. 60, 74, 94, 95) y que como lo expresa tanto en El concepto de la angustia (Kierkegaard, 2016, p.152, 156), así como en El Postscriptum (2009), es el núcleo del devenir, o el venir a la existencia del individuo en el tiempo y que no depende, ni se deriva, de ninguna necesidad natural, o de algún esquema lógico, por ello cualifica al individuo como tal, y no en algún aspecto u otro. Es por el cual el futuro ingresa como presente y se hace porvenir, como dice En la espera de la fe (Kierkegaard, 2005, p. 53).

9 Se podría tematizar que esta tensión de lo cómico y lo trágico en el humor es otro modo de expresar la estructura antropológica del individuo como síntesis de cuerpo, alma y espíritu, como aparece en El concepto de la angustia (Kierkegaard, 2016, p. 159).

10 Nos referimos a la idea del yo o del sujeto en la filosofía moderna que inicia con René Descartes, por lo que el yo no se identifica con una persona en todas sus dimensiones y su integridad, sino esencialmente con la identidad autoconsciente de su propia estructura mental y que a través de las historia del pensamiento moderno cobra diversas formas y características. Por ello el yo puede ser equivalente a un sistema lógico que puede concretarse como entidades no personales: un estado político, o un sistema ideológico, o convenciones sociales, etc. Por ello cuando Kierkegaard habla del pensador objetivo se refiere a esta idea del yo moderno en las claves del idealismo alemán, particularmente el de Hegel y el pensador subjetivo es precisamente, el que no se identifica con este tipo de yo, sino con la persona concreta.

11 Dicho sea de paso muchos de los personajes principales de Woody Allen son mujeres reflexivas, probablemente porque la contradicción entre la reflexión y la sensibilidad sea más acentuada o tal vez también porque en una mujer hay más esperanzas de vencer esta idea del sujeto de la modernidad.

12 Kierkegaard en su estudio sobre "El reflejo de lo trágico antiguo en lo trágico moderno" en O lo uno o lo otro. Un fragmento de vida I (2006) comenta que nuestro mundo moderno se ha esforzado por facilitar "la transustanciación de lo fatal en individualidad y en subjetividad" (p. 163).

13 Sin dar una sinopsis completa del filme, en general, en ambas historias, Melinda, aparece sin razón alguna en medio de una cena. En la versión trágica, los que cenan guardan con Melinda una relación pasada de amistad, y de amores ocultos o reprimidos, que durante el desarrollo de la historia serán los motivantes de las culpas, y penas que Melinda cargará sobre sí; y que en el amor de un hombre desconocido creerá poder resolverlas, sin embargo, no será así y su incapacidad de conciliación terminarán en una neurosis que no podrá controlar. En cambio, la Melinda cómica es como una extranjera que nada tiene que ver con los que cenan, por lo cual se vuelve una situación absurda, y aún más ridícula, porque el anfitrión de ésta, Hobie (Will Ferrel), se sentirá inexplicablemente enamorado de ella. La situación cómica se dará por la contradicción entre un sentido de la responsabilidad matrimonial, por un matrimonio que no existe, pues su mujer, que es un personaje controlador y dominante, lo ha hecho ser un hombre inexistente. Pero lo cómico se tornará lo serio cuando Hobie al sentirse liberado de este deber, porque encuentra a su esposa siéndole infiel, Melinda le confiesa estar enamorado de otro, lo cual termina poniendo las cosas en su justo lugar y liberando a Hobie, y a Melinda para nuevas posibilidades, siendo sorprendidos recíprocamente por su amor mutuo. 